\title{
ESTIMATED DAILY INTAKE OF BENZOIC ACID THROUGH FOOD ADDITIVES IN ADULT POPULATION OF SOUTH EAST SERBIA
}

\author{
Konstansa Lazarević ${ }^{1}$, Dušica Stojanović ${ }^{1,2}$, Nataša Rančić ${ }^{1,2}$ \\ ${ }^{1}$ Public Health Institute, Niš, Serbia \\ ${ }^{2}$ School of Medicine, University of Niš, Serbia
}

\begin{abstract}
SUMMARY
The aim of this study is to estimate dietary intake of benzoic acid and its salts through food additives in adult population of South East Serbia. Information on dietary intake among 620 adults (aged 18-65) was collected using a food frequency questionnaire, and 748 food samples were analyzed.

The mean estimated intake of benzoic acid $-0.32 \mathrm{mg} / \mathrm{kg}$ of body weight (bw) per day was below acceptable daily intake (ADI). Dietary exposure to benzoic acid $(0.36 \mathrm{mg} / \mathrm{kg}$ of bw/day; $7.2 \% \mathrm{ADI}$ ) (consumer only), also did not exceed ADI. The main contributors of benzoic acid to dietary intake were non alcoholic beverages (43.1\%), ketchup and tomato products (36.1\%), and domestic pickled vegetables (19.4\%).

The results of this study indicate that dietary exposure to benzoic acid and its salts through food preservatives does not represent a public health risk for the adult population of South East Serbia.
\end{abstract}

Key words: benzoic acid, food additive, dietary intake

Address for correspondence: K. Lazarević, Public Health Institute Niš, Dr Z Djindjica 50, 18000 Niš, Serbia. E- mail: koni33@hotmail.com

\section{INTRODUCTION}

Benzoic acid and its salts (benzoate) may naturally be present in food, but with their antimicrobial properties they have a long history of use as food preservatives. Their use as food additives was limited by Joint FAO/WHO Expert Committee on Food Additives (JECFA). According to JECFA acceptable daily intakes (ADI) of $0-5 \mathrm{mg} / \mathrm{kg}$ body weight for benzoic acid and benzoate have been established (1).

Acute toxicity of benzoic acid as a food additive is low. However, it was observed that in sensitive persons, intake of benzoic acid lower than $5 \mathrm{mg} / \mathrm{kg}$ of body weight per day, can cause non-immunological contact reactions (pseudoallergy) (2). Some studies suggested that very high intake of benzoic acid can cause adverse health effects such as metabolic acidosis, hyperpnoea and convulsions (1). Few epidemiologic studies reported allergic reactions to benzoic acid and benzoate (urticaria, rinhitis and pruritis) (3-5). For this reason, estimation of daily intake of these additives is of public health concern.

The purpose of this study was to estimate a daily intake of benzoic acid via food additives in adult population of South East Serbia.

\section{MATERIALS AND METHOD}

The study was conducted from 2008-2010, on a random sample of 620 citizens (313 men and 307 women) of South East Serbia (Nisava district) aged 18 to 65 drawn from the Central Population Register. Subjects were informed about the aims of the study and all of them agreed to take part in the study.
The structured questionnaire included personal information (name, gender, education) and life style habits (smoking and dietary habits). Body weight was self-reported during this interview.

Modified self administered food frequency questionnaires (FFQ) based on those by Willet (6) were used, as seasonal differences between the subjects' food intake might have influenced the total intake estimation. A FFQ was used to assess subjects' habitual diet, including information on weekly frequency of consumption of specific foods (98 items) in course of 1 year prior to interview.

For foods, there were 9 possible responses ranging from never to $>5$ times per day. The frequency category "Never or less than once a month", used by Willett, has been separated into two different categories "never" and "less than once a month". The frequency category "never" is necessary when the objective is to distinguish consumers from non-consumers.

The accredited laboratory of the Public Health Institute Nis determined the content of benzoic acid in 748 foodstuffs from domestic production and import. Results are expressed as benzoic acid equivalents. Benzoic acid and their salts were determined using spectrophotometry method, which was accredited according to ISO 17025. The determination of benzoic acid was performed according to the adapted and validated official method of analysis (Official gazette SFRJ no. 29/83) (7).

The mean dietary intake of benzoic acid was estimated according to the equation:

$$
\mathrm{Yi}=\sum(\mathrm{Xvi} * \mathrm{Cv}) / \mathrm{bwi}
$$

where Xvi is the average daily amount $(\mathrm{kg})$ of a food item that contains benzoic acid or benzoates (as food additive), consumed by subjects of this study $\mathrm{i}$, and $\mathrm{Cv}$ is concentration of benzoic acid 
in that food item expressed in $\mathrm{mg} / \mathrm{kg}$ foodstuff, and bwi is the subject's body weight $(\mathrm{kg})$. Several foodstuffs, in which benzoic acid and benzoate use is allowed, were not taken into account because of their assumed low consumption: low sugar marmalade, beverages (ice tea, energy drink), non heat treated dairy based dessert, emulsified sauces $(<60 \%$ fat or $>60 \%)$, mustard, and semi-preserved fish products.

Not all subjects included in the study stated consumption of foods containing these preservatives. Those subjects who reported consumption of foods containing benzoic acid and its salts as food additives were termed as consumers.

\section{RESULTS}

The values of benzoic acid in all of analyzed food samples did not exceed the maximum permitted level (Table 1). The Draft of the Regulations stipulates maximum allowed concentrations of benzoic in foodstuffs (maximum permitted level $[\mathrm{mg} / \mathrm{kg}$ or $\mathrm{mg} / 1$ - MPL) (8-10). In 85 samples of 748 analyzed foodstuffs, benzoic acid was not detected (limit of detection $5 \mathrm{mg}$ benzoic $\mathrm{acid} / \mathrm{kg}$ or 1$)$.

Non alcoholic beverages include non cola beverages, cola beverages, syrup, ice tea and energy drinks. Serbian regulative for non alcoholic beverages is in accordance with EU legislation which established the maximum permitted levels of $150 \mathrm{mg} / \mathrm{l}$ for benzoic acid (8-10).

Table 2 shows percentage of food consumers and data of daily food intake (mean, standard deviation) of the food group in which the addition of benzoic acid is permitted for a total population of this study.

Most of study subjects reported consumption of: non alcoholic beverages $(85.5 \%)$, ketchup and tomato products $(81.8 \%)$ and pickled vegetables (home production) (91.1\%) (Table 2).

Table 3 shows estimated daily intake of benzoic acid for all study population and consumer only for each food group separately.

It was observed that the mean intake of benzoic acid per day was much lower than ADI ( $5 \mathrm{mg} / \mathrm{kg}$ of body weight), by the whole

Table 1. Number of samples of food when benzoic acid is detected ( $>5 \mathrm{mg} / \mathrm{kg})$, analytic level and maximum permitted level (mg/kg or mg/l) (MPL) of benzoic acid

\begin{tabular}{|l|c|c|c|}
\hline \multirow{2}{*}{ Food group } & \multicolumn{2}{|c|}{ Benzoic acid } \\
\cline { 2 - 4 } & $\begin{array}{c}\text { Number of samples when } \\
\text { detected/al samples }\end{array}$ & $\begin{array}{c}\text { Mean analytic level } \\
\text { (range) }\end{array}$ & MPL \\
\hline Non alcoholic beverages & $615 / 639$ & $79.6(<5-149)$ & 150 \\
\hline Non-cola beverages & $439 / 439$ & $86.4(8-149)$ & 150 \\
\hline Cola beverages & $87 / 111$ & $65.3(<5-127)$ & 150 \\
\hline Syrup & $85 / 85$ & $45.4(18-87)$ & 150 \\
\hline Ice tea & $2 / 2$ & $66.3(28-104.7)$ & 150 \\
\hline Energy drink & $2 / 2$ & $69.4(65-73.7)$ & 150 \\
\hline Low sugar marmalade & $6 / 8$ & $396.7(<5-400)$ & 500 \\
\hline Pickled vegetables (home production) & $17 / 17$ & $424.8(129-650)$ & - \\
\hline Pickled vegetables (industrial) & $10 / 50$ & $136.0(<5-750)$ & $2000^{*}$ \\
\hline Ketchup and tomato products & $10 / 14$ & $534.7(<5-962)$ & 1000 \\
\hline Olive & $5 / 20$ & $211.8(<5-500)$ & 500 \\
\hline$\Sigma$ & $663 / 748$ & & \\
\hline
\end{tabular}

* (with sorbic acid)

Table 2. Percentage of consumers and daily intake of food group in which the addition of benzoic acid is permitted

\begin{tabular}{|l|c|c|c|}
\hline \multirow{2}{*}{ Food group } & \multirow{2}{*}{ Percentage of consumers (\%) } & Mean & Standard deviation \\
\cline { 3 - 4 } & & & \\
\hline Non alcoholic beverages & 85.5 & 68.8 & 107.1 \\
\hline Non cola beverages & 79.2 & 64.6 & 85.2 \\
\hline Cola beverages & 85.5 & 11.8 & 26.9 \\
\hline Syrup & 42.7 & 11.7 & 9.3 \\
\hline Pickled vegetables (home production) & 91.1 & 0.67 & 1.5 \\
\hline Pickled vegetables (industrial) & 45.3 & 17.4 & 23.7 \\
\hline Ketchup and tomato products & 81.8 & 0.78 & 1.7 \\
\hline Olive & 63.7 & & \\
\hline
\end{tabular}


Table 3. The estimated daily intake of benzoic acid via different food groups for all study subjects and consumer only

\begin{tabular}{|l|c|c|c|c|c|}
\hline \multirow{2}{*}{ Food group } & \multicolumn{5}{|c|}{ Benzoic acid intake (mg/kg/bw) } \\
\cline { 2 - 6 } & \multicolumn{2}{|c|}{ All study population } & \multicolumn{3}{|c|}{ Consumer only } \\
\cline { 2 - 6 } & Mean & $\begin{array}{c}\text { Standard } \\
\text { deviation }\end{array}$ & Mean & $\begin{array}{c}\text { Standard } \\
\text { deviation }\end{array}$ & \\
\hline Non alcoholic beverages & & & & & \\
\hline Non cola beverages & 0.07 & 0.10 & 0.09 & 0.11 & 0.29 \\
\hline Cola beverages & 0.05 & 0.06 & 0.05 & 0.07 & 0.17 \\
\hline Syrup & 0.006 & 0.015 & 0.015 & 0.02 & 0.04 \\
\hline Pickled vegetables (home production) & 0.07 & 0.05 & 0.07 & 0.05 & 0.003 \\
\hline Pickled vegetables (industrial) & 0.001 & 0.002 & 0.002 & 0.16 & 0.46 \\
\hline Ketchup and tomato products & 0.12 & 0.16 & 0.13 & 0.005 & 0.006 \\
\hline Olive & 0.002 & 0.004 & 0.003 & & 0.005 \\
\hline$\Sigma$ & 0.32 & & 0.36 & & 1.13 \\
\hline
\end{tabular}

Table 4. The estimated daily intake of benzoic acid or percentage of intake and percentage of ADI via different food groups based on intake of consumers-only

\begin{tabular}{|l|c|c|c|c|}
\hline \multirow{2}{*}{ Food group } & \multicolumn{4}{|c|}{ Benzoic acid (mg/kg/bw) } \\
\cline { 2 - 5 } & Mean & Min-max & Percentage of intake (\%) & Percentage of ADI (\%) \\
\hline Non alcoholic beverages & & & 43.1 & 3.1 \\
\hline Non cola beverages & 0.09 & $0.006-0.61$ & 25 & 1.8 \\
\hline Cola beverages & 0.05 & $0.005-0.46$ & 13.9 & 1.0 \\
\hline Syrup & 0.015 & $0.003-0.17$ & 4.2 & 0.3 \\
\hline Pickled vegetables (home production) & 0.07 & $0.0003-0.18$ & 19.4 & 1.4 \\
\hline Pickled vegetables (industrial) & 0.002 & $0.003-0.25$ & 0.6 & 0.04 \\
\hline Ketchup and tomato products & 0.13 & $0.003-0.71$ & 36.1 & 2.6 \\
\hline Olive & 0.003 & $0.0003-0.038$ & 0.8 & \\
\hline$\sum$ & $\mathbf{0 . 3 6}$ & & & 0.06 \\
\hline
\end{tabular}

study population $(0.32 \mathrm{mg} / \mathrm{kg}$ of body weight), and consumer as well $(0.36 \mathrm{mg} / \mathrm{kg}$ of body weight). The estimate of daily intake by consumers with high intake (at the 95 percentile), was also below ADI (1.13 mg/kg of body weight) (Table 3 ).

Table 4 shows a proportion of daily intake of benzoic acid for consumers only.

The mean estimated intake of benzoic acid ( $7.2 \%$ of ADI) was below the ADI, but the greatest contributor to the total estimated benzoic acid intake was a group of non alcoholic beverages (43.1\%) and group of ketchup and tomato products (36.1\%). Other important contributors to benzoic acid exposure in consumer were pickled vegetables from home production (19.4\%) (Table 4).

\section{DISCUSSION}

In the present study, the concentration of preservatives (benzoic acid) was in all food samples within official limits. Also, it is evident that a group of non alcoholic beverages was the main source of benzoic acid. Similar situation is in other countries around the world, where the main dietary source of benzoic acid are non alcoholic beverages (11). The analytical results of the current study showed that mean levels of benzoic acid in non alcoholic beverages were lower than those found in most of other studies from Portugal (12), Brazil (13), Belgium (14), United Kingdom (15) and USA (16). In the study from Korea (17) benzoic acid was not detected in carbonated beverages and in our study in some samples of cola beverages.

Most European countries have estimated the dietary intake of benzoic acid. According to the Council of Europe, percentage of ADI for benzoic acid via food additive in adults, in Denmark, Estonia, France, Italy, Netherlands, United Kingdom and Norway were below the ADI (18). Information from other studies from Denmark (19) and Belgium (14) and studies from around the world (Brazil (13), Australia (20), New Zealand (21), Korea (17) and Japan (22) also indicated the intake of benzoic acid below ADI.

The evaluated data are not adequate for comparison. In most of these studies (18), but not in all $(13-15,19,21,22)$, the estimation of daily intake of benzoic acid via food additives was based on maximum limits of food additives specified in national food standard. 
In our research we used analytical values of preservatives (benzoic acid and its salts) content in foods which are essential for estimating their daily intake.

It is important to note that FFQ shows that the main contributors to the dietary exposure of benzoic acid are not regularly consumed. Domestic pickled vegetables (from home production with added preservative sodium benzoate) are Serbian national food consumed only few months (3-4 month) per year, and consumption of non alcoholic beverages is higher in summer months. Thus, in those months intake of benzoic acid is much higher. Also, non alcoholic beverages have low biological values, and they are not part of healthy diet.

Based on the results of this study, which objective was reduction of the intake of benzoic acid, it is felt appropriate to recommend pasteurization of vegetables and using high-pressure sterilization, (where possible), and moderate consumption of non alcoholic beverages.

However, the results of this study indicate that dietary intake of benzoic acid via food additives in adult population of South East Serbia does not represent a public health risk.

\section{REFERENCE}

1. World Health Organization. Evaluation of certain food additives: fortysixth report of the Joint FAO/WHO Expert Committee on Food Additives. WHO Technical Report Series No. 868. Geneva: WHO; 1997.

2. World Health Organization. Benzoic acid and sodium benzoate. Concise international chemical assessment document 26. Geneva: WHO; 2000.

3. Nettis E, Colanardi MC, Ferrannini A, Tursi A. Sodium benzoate-induced repeated episodes of acute urticaria/angio-oedema: randomized controlled trial. Br J Dermatol. 2004 Oct;151(4):898-902.

4. Asero R. Sodium benzoate-induced pruritus. Allergy. 2006 Oct;61(10):1240-1.

5. Pacor ML, Di Lorenzo G, Martinelli N, Mansueto P, Rini GB, Corrocher R. Monosodium benzoate hypersensitivity in subjects with persistent rhinitis. Allergy. 2004;59(2):192-7.

6. Willet W. Nutritional epidemiology. New York: Oxford University Press; 1990.

7. Regulation on methodology for sampling and conducting of chemical and physical analysis to determine the quality of fruit and vegetable products. Official Gazette SFRJ. 1983;(29).

8. Regulation on quality and conditions for use of additives in foodstuffs and about other requirements for additives and their mixtures. Official Gazette SCG. 2003;(56).
9. Regulation on quality and conditions for use of additives in foodstuffs and about other requirements for additives and their mixtures. Official Gazette SCG. 2004;(5).

10. Regulation on quality and conditions for use of additives in foodstuffs and about other requirements for additives and their mixtures. Official Gazette SCG. 2005(16).

11. World Health Organization. Evaluation of certain food additives and contaminants: fifty-first report of the Joint FAO/WHO Expert Committee on Food Additives. WHO Technical Report Series No. 891. Geneva: WHO; 2000

12. Lino CM, Pena A. Occurrence of caffeine, saccharin, benzoic acid and sorbic acid in soft drinks and nectars in Portugal and subsequent exposure assessment. Food Chem. 2010;121(2):503-8.

13. Tfouni SA, Toledo MC. Estimates of the mean per capita daily intake of benzoic and sorbic acids in Brazil. Food Addit Contam. 2002 Jul;19(7):647-54.

14. Vandevijvere S, Andjelkovic M, De Wil M, Vinkx C, Huybrechts I, Van Loco J, et al. Estimate of intake of benzoic acid in the Belgian adult population. Food Addit Contam Part A Chem Anal Control Expo Risk Assess. 2009 Jul;26(7):958-68.

15. Food Standard Agency. Food surveillance information sheet 65 [Internet]. London: Food Standard Agency; 1995 [cited 2010 Dec 5]. Available from: http://archive.food.gov.uk/maff/archive/food/infsheet/1995/ no65/65sulben.htm.

16. Walker JC, Zaugg SE, Walker EB. Analysis of beverages by capillary electrophoresis. J Chromatogr A. 1997;781(1-2):481-5.

17. Yoon HJ, Cho YH, Park J, Lee CH, Park SK, Cho YJ, et al. Assessmen of estimated daily intakes of benzoates for average and high consumers in Korea. Food Addit Contam. 2003 Feb;20(2):127-35.

18. European Commission. Report from the Commission on Dietary Food Additive Intake in the European Union. Brussels: European Commission; 2001.

19. Leth T, Christensen T, Larsen IK. Estimated intake of benzoic and sorbic acids in Denmark. Food Addit Contam Part A Chem Anal Control Expo Risk Assess. 2010 Jun;27(6):783-92.

20. Food Standards Australia and New Zealand (FSANZ). Benzoates, sulphites and sorbates in the food supply [Internet]. Canberra: FSANZ; 2005 [cited 2010 Dec 5]. Available from: http://www.foodstandards.gov.au/scienceandeducation/factsheets/factsheets2005/benzoatessulphitesan2965. cfm.

21. Cressey P, Jones S. Levels of preservatives (sulfite, sorbate and benzoate) in New Zealand foods and estimated dietary exposure. Food Addit Contam Part A Chem Anal Control Expo Risk Assess. 2009 May;26(5):604-13.

22. Ishiwata H, Yamada T, Yoshiike N, Nishijima M, Kawamoto A, Uyama Y. Daily intake of food additives in Japan in five age groups estimated by the market basket method. Eur Food Res Technol. 2002;215(5):367-74.

Received December 5, 2010 Accepted in revised form July 12, 2011 